\title{
Antiandrogens Reduce Intratumoral Androgen Concentrations and Induce Androgen Receptor Expression in Castration-Resistant Prostate Cancer Xenografts
}

Matias Knuuttila, ${ }^{* \dagger}$ Arfa Mehmood, ${ }^{\ddagger}$ Riikka Huhtaniemi, ${ }^{\star \dagger \S}$ Emrah Yatkin, ${ }^{* \dagger}$ Merja R. Häkkinen, ${ }^{\Uparrow}$ Riikka Oksala, Teemu D. Laajala, ${ }^{\dagger \| * *}$ Henrik Ryberg, ${ }^{\dagger \dagger}$ David J. Handelsman, ${ }^{\ddagger \dagger}$ Tero Aittokallio, ${ }^{\dagger \dagger * *}$ Seppo Auriola, ${ }^{\top}$ Claes Ohlsson, Asta Laiho, ${ }^{\ddagger}$ Laura L. Elo, ${ }^{\ddagger \|}$ Petra Sipilä, ${ }^{* \dagger}$ Sari I. Mäkelä, ${ }^{\dagger \S}$ and Matti Poutanen ${ }^{* \dagger, \dagger \dagger}$

From the Department of Physiology* and the Turku Center for Disease Modeling, ${ }^{\dagger}$ Institute of Biomedicine, the Department of Mathematics and Statistics, and the Functional Foods Forum, ${ }^{\S \S}$ University of Turku, Turku, Finland; the Turku Centre for Biotechnology, ${ }^{\ddagger}$ University of Turku and Åbo Akademi University, Turku, Finland; the R\&D Oncology Research, ${ }^{\S}$ Orion Pharma, Turku, Finland; the School of Pharmacy, "University of Eastern Finland, Kuopio, Finland; the Institute for Molecular Medicine Finland, ** University of Helsinki, Helsinki, Finland; the Center for Bone and Arthritis Research, ${ }^{\dagger \dagger}$ The Sahlgrenska Academy, Gothenburg University, Gothenburg, Sweden; and the ANZAC Research Institute, 㧊 University of Sydney, Concord, New South Wales, Australia

Accepted for publication August 28, 2017.

Address correspondence to Matti Poutanen, Ph.D., Department of Physiology, Institute of Biomedicine, University of Turku, Kiinamyllynkatu 10, 20520 Turku, Finland. E-mail: matti.poutanen@utu.fi.

\begin{abstract}
The development of castration-resistant prostate cancer (CRPC) is associated with the activation of intratumoral androgen biosynthesis and an increase in androgen receptor (AR) expression. We recently demonstrated that, similarly to the clinical CRPC, orthotopically grown castration-resistant VCaP (CR-VCaP) xenografts express high levels of AR and retain intratumoral androgen concentrations similar to tumors grown in intact mice. Herein, we show that antiandrogen treatment (enzalutamide or ARN-509) significantly reduced $(10$-fold, $P<0.01)$ intratumoral testosterone and dihydrotestosterone concentrations in the CR-VCaP tumors, indicating that the reduction in intratumoral androgens is a novel mechanism by which antiandrogens mediate their effects in CRPC. Antiandrogen treatment also altered the expression of multiple enzymes potentially involved in steroid metabolism. Identical to clinical CRPC, the expression levels of the full-length AR (twofold, $P<0.05$ ) and the AR splice variants 1 (threefold, $P<0.05$ ) and 7 (threefold, $P<0.01$ ) were further increased in the antiandrogen-treated tumors. Nonsignificant effects were observed in the expression of certain classic androgen-regulated genes, such as TMPRSS2 and KLK3, despite the low levels of testosterone and dihydrotestosterone. However, other genes recently identified to be highly sensitive to androgen-regulated AR action, such as NOV and ST6GalNAc1, were markedly altered, which indicated reduced androgen action. Taken together, the data indicate that, besides blocking AR, antiandrogens modify androgen signaling in CR-VCaP xenografts at multiple levels. (Am J Pathol 2018, 188: 216-228; https://doi.org/10.1016/j.ajpath.2017.08.036)
\end{abstract}

Prostate cancer is one of the most common cancers in men from Western countries. ${ }^{1}$ Most aging men develop precancerous lesions, and one of eight men are diagnosed as having prostate cancer. Androgen deprivation therapy (ADT) suppresses the growth of prostate cancer via blockade of testicular androgen production. Androgen deprivation is achieved via treatment of patients with luteinizing hormone-releasing hormone agonists or antagonists, which can be combined
Supported by a Academy of Finland grant (T.A., L.L.E., and M.P.), a Cancer Society of Finland grant (T.A. and M.P.), a European Research Council grant (L.L.E.), the European Union Horizon 2020 Research and Innovation Program (L.L.E.), a Juvenile Diabetes Research Foundation grant (L.L.E.), a Sigrid Juselius Foundation grant (L.L.E. and M.P.), the Finnish Cultural Foundation (M.K.), and an Orion Pharma grant (M.P.).

Disclosures: None declared. 
with antiandrogens that block the effects of any residual androgen action. ${ }^{2}$ ADT typically causes a decline in serum prostate-specific antigen (PSA), but the response is transient for a significant proportion of men; the disease eventually progresses to fatal castration-resistant prostate cancer (CRPC). The average time to develop CRPC after the initiation of ADT is $<2$ years, and the prognosis for patients with CRPC is poor.

It is now well established that CRPC is an androgen-regulated disease. The development of CRPC is associated with aberrant androgen receptor (AR) expression ${ }^{4}$ and activation of intratumoral androgen biosynthesis, ${ }^{5}$ and the expression of AR target genes (eg, KLK3 and TMPRSS2) is retained as a consequence. These findings have promoted the development of new therapeutic strategies for CRPC to target androgen action via inhibition of androgen biosynthesis or a more efficient blockade of AR action. These novel strategies include the cytochrome P450 (CYP) 17A1 inhibitor (abiraterone acetate) and new AR antagonists (enzalutamide, ARN-509, and ODM-201). Enzalutamide and ARN-509 possess similar structures and preclinical properties, ${ }^{6}$ whereas ODM- $201^{7}$ is structurally distinct from the two above-mentioned antagonists. In vitro studies have demonstrated that enzalutamide and ARN-509 affect AR signaling at three separate stages: i) blockade of androgen binding to AR, ii) inhibition of AR nuclear translocation, and iii) weakening of AR binding to DNA. ${ }^{6,8}$

The AR gene copy number, and consequently transcription, is often increased in CRPC, causing up-regulation of $\mathrm{AR}$ expression and resulting in sensitization of the cancer cells to low levels of androgens. ${ }^{9}$ Increased expression of AR splice variants has also been observed in CRPC tumors and metastases. ${ }^{10}$ Several different AR splice variants that lack the ligand-binding domain have been detected, and especially the expression of AR splice variant (AR-V) 7 is markedly elevated in CRPC. ${ }^{11}$ AR splice variant expression is up-regulated after ADT when circulating androgen levels are low, which suggests that AR splice variant levels may increase as a result of androgen blockade. ${ }^{12}$

Preclinical models provide valuable information on the regulation of CRPC growth. The $\mathrm{VCaP}$ cell line, which originated from a vertebral metastasis of prostate cancer, is one of the recent CRPC models. VCaP cells are androgen sensitive, are tumorigenic, and express AR and several other markers associated with CRPC growth, such as retinoblastoma protein $(R B 1)$, p53 (TP53), PSA (KLK3), and the TMPRSS2-ERG fusion gene. ${ }^{13,14}$ Furthermore, VCaP cells also express enzymes involved in intratumoral androgen biosynthesis, such as CYP17A1, AKRIC3, and HSDI7B6. ${ }^{15,16}$ We recently demonstrated that $\mathrm{VCaP}$ xenograft tumors, grown orthotopically (o.t.) in immunodeficient mice, exhibit key properties of CRPC (namely, regrowth after castration, AR overexpression, upregulation of AR splice variants, increased expression of steroidogenic enzymes, and activation of intratumoral androgen biosynthesis). ${ }^{16}$ The present study further characterized the antiandrogen responses in o.t. castration-resistant $\mathrm{VCaP}$ tumors (CR-VCaP).

\section{Materials and Methods}

\section{Cell Culture}

VCaP cells were purchased in 2006 from ATCC (Manassas, VA) and tested and authenticated by the authors using short tandem-repeat analysis in 2014. Cells were grown in vitro $\left(37^{\circ} \mathrm{C}, 5 \% \mathrm{CO}_{2}\right)$ in phenol red-free RPMI 1640 medium (Sigma-Aldrich, St. Louis, MO) on $75-\mathrm{cm}^{2}$ Corning CellBind flasks (Corning Life Sciences, Tewksbury, MA), supplemented with $10 \%$ fetal bovine serum (Biowest, Nuaillé, France), 2\% L-glutamine (Gibco, Carlsbad, CA), and $1 \%$ penicillin/streptomycin (Sigma-Aldrich). The cells were split 1:2 once weekly, and the medium was changed every other day. The cells were counted and suspended in serum-free RPMI 1640 medium before inoculation.

\section{Treatment of Castration-Resistant Orthotopic VCaP Tumors with Antiandrogens}

Adult male immunodeficient mice (HSD/athymic nude-Foxn $1^{n u}$ ) were purchased from Harlan Laboratories (Indianapolis, IN) and housed under controlled conditions in specific pathogen-free conditions at the Central Animal Laboratory, University of Turku (Turku, Finland) in compliance with international guidelines on the care and use of laboratory animals. Mice were provided with irradiated soy-free natural-ingredient feed [RM3 (E); Special Diets Services, Essex, UK] and autoclaved tap water ad libitum. All animal handling was performed in accordance with our license from the Finnish Animal Ethics Committee (license number 1993/04.10.03/2011) and the institutional animal care policies, which fully meet the requirements of the US National Institutes of Health guidelines on animal experimentation. One million VCaP cells in $20 \mu \mathrm{L}$ medium were o.t. inoculated into the dorsolateral prostate through an abdominal incision. Mice were provided anesthesia and analgesia, and blood sampling and PSA measurements were performed, as described previously. ${ }^{16}$ Tumor growth was followed by measuring serum PSA once weekly.

The CR-VCaP xenograft model has been previously described. ${ }^{16}$ Briefly, o.t. VCaP tumors were allowed to grow for 4 to 5 weeks until at least $60 \%$ of animals reached a serum PSA $>5 \mu \mathrm{g} / \mathrm{L}$, and the mean serum PSA value for the study cohort was approximately $15 \mu \mathrm{g} / \mathrm{L}$. Mice with tumors were castrated, causing a dramatic decline in serum PSA, which was observed 1 week after castration. Subsequently, the serum PSA concentrations started increasing, indicating CRPC-like tumor growth, and the treatment began when the serum PSA of all castrated mice reached precastration levels. The mice were allocated to the treatment arms on the basis of the following five parameters: serum PSA concentration, the change in the serum PSA concentration, body weight, cage placement, and the week at which castration occurred. ${ }^{17}$ The vehicle $(n=15)$ or antiandrogens $[20 \mathrm{mg} / \mathrm{kg}$ per day of enzalutamide $(n=14)$ or ARN-509 $(n=15)$; Matrix 
Table 1 Real-Time Quantitative RT-PCR Primer Sequences

\begin{tabular}{|c|c|c|}
\hline \multirow[b]{2}{*}{ Gene } & \multicolumn{2}{|l|}{ Primer sequence } \\
\hline & Forward & Reverse \\
\hline$A R-F L$ & $5^{\prime}$-CTTACACGTGGACGACCAGA-3' & 5'-GCTGTACATCCGGGACTTGT-3' \\
\hline$A R-V 7$ & 5'-CCATCTTGTCGTCTTCGGAAATGTTATGAAGC-3' & 5'-TTTGAATGAGGCAAGTCAGCCTTTCT-3' \\
\hline ASF/SF2 & $5^{\prime}-$ TCTCTGGACTGCCTCCAAGT-3' & $5^{\prime}$-GGCTTCTGCTACGACTACGG-3' \\
\hline FKBP5 & $5^{\prime}-$ AAAAGGCCACCTAGCTTTTTGC-3' & $5^{\prime}$-CCCCCTGGTGAACCATAATACA-3' \\
\hline NOV & $5^{\prime}$-ACCGTCAATGTGAGATGCTG-3' & 5'-TCTTGAACTGCAGGTGGATG-3' \\
\hline PMEPA1 & 5'-TGCCGTTCCATCCTGGTT-3' & $5^{\prime}-$ AGACAGTGACAAGGCTAGAGAAAGC $-3^{\prime}$ \\
\hline RPL19 & $5^{\prime}$-AGGCACATGGGCATAGGTAA-3' & $5^{\prime}$-CCATGAGAATCCGCTTGTTT-3' \\
\hline ST6GalNAc1 & 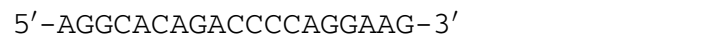 & $5^{\prime}-\mathrm{TGAAGCCATAAGCACTCACC-3^{ \prime }}$ \\
\hline SYTL2 & 5'-TCTGCCTTGAGAAAACAAACAGTT-3' & $5^{\prime}$-GCCAGTGGGTGGCACTAAAA- $3^{\prime}$ \\
\hline
\end{tabular}

Scientific, Columbia, SC] were administered via gavage once daily. Previous studies suggested that a 4-week treatment time period may be optimal to mimic the effects of antiandrogen treatment in CRPC and show how CR-VCaP tumors adapt to antiandrogens. ${ }^{16}$ The mice were sacrificed via cervical dislocation after 4 weeks of treatment, and the tumors were dissected and measured. Fresh tissue sample pieces from each tumor were collected in liquid nitrogen and fixed in $10 \%$ formalin for 24 hours before paraffin embedding.

\section{DHT Uptake in the Castration-Resistant VCaP Tumors}

Immunodeficient male mice with s.c. CR-VCaP tumors were given a single dose of enzalutamide $(n=6,20 \mathrm{mg} / \mathrm{kg})$ or vehicle $(n=6)$. Tritium-labeled dihydrotestosterone ([1,2,4,5,6,7-3H(N)]- ${ }^{3} \mathrm{H}-\mathrm{DHT} ; 110 \mathrm{Ci} / \mathrm{mmol}$; PerkinElmer, Waltham, MA), dissolved in ethanol/saline (20:80) solution, was injected i.v. into the tail vein of mice (approximately $1.6 \mathrm{MBq} / \mathrm{mouse}) 4$ hours later. Blood samples were collected via cardiac puncture in anesthetized mice 15 minutes after the injection. Mice were sacrificed via cervical dislocation, and the tumor samples were collected. Tumors were homogenized in sterile water using an Ultra Turrax homogenizer (IKA-Werke, Staufen im Breisgau, Germany). Tumor homogenates $(1.5 \mathrm{~mL})$ and serum samples $(100 \mu \mathrm{L})$ were mixed with $10 \mathrm{~mL}$ Ecoscint A scintillation liquid (National Diagnostics, Atlanta, GA), and the radioactivity of the samples was measured using a Wallac 1410 liquid scintillation counter (PerkinElmer).

\section{Intratumoral and Serum Steroid Measurements}

Tumor samples were homogenized in sterile water using a Tissuelyzer LT homogenizer (Qiagen, Venlo, the Netherlands), and the concentrations of androstenedione, testosterone (T), and DHT were measured from the tumor homogenates and serum samples using gas chromatography-tandem mass spectrometry. ${ }^{18}$ The lower limits of quantitation (LLOQs) for androstenedione, $\mathrm{T}$, and DHT in mouse serum samples were 12,8 , and $2.5 \mathrm{pg} / \mathrm{mL}$, respectively. The concentrations of pregnenolone and progesterone were measured in the tumor homogenates and serum samples using liquid chromatography-tandem mass spectrometry. ${ }^{19}$ The LLOQs for pregnenolone and progesterone in serum samples were 10.4 and $10.7 \mathrm{pg} / \mathrm{mL}$, respectively. The concentrations of $3 \alpha$-androstanediol $(3 \alpha-$ diol) and $3 \beta$-androstanediol ( $3 \beta$-diol) were measured in the tumor homogenates using liquid chromatography-tandem mass spectrometry; the lower limit of detection (LLOD) for $3 \alpha$ - and $3 \beta$-diol was $400 \mathrm{pg} / \mathrm{mL}^{20}$ The LLOQ was used for statistical analysis if steroid concentrations in samples were lower than the quantitation limit. One gram of tumor sample was considered equivalent to $1 \mathrm{~mL}$ of serum to compare intratumoral steroid levels with serum steroid levels.

\section{Real-Time RT-qPCR and RNA-Seq Analysis}

Total RNA for real-time quantitative RT-PCR (RT-qPCR) and RNA-sequencing (RNA-seq) analyses was extracted from tumor samples using an RNase Mini Kit (Qiagen), according to the manufacturer's instructions. RNA was DNase I treated (amplification grade; Invitrogen, Carlsbad, CA), and RNA quality was determined using a fragment analyzer (Advanced Analytical Technologies, Ankeny, IA). RNA was reverse transcribed using M-MuLV Reverse Transcriptase (New England Biolabs, Ipswich, MA) in the presence of oligo(dT) primers (Promega, Fitchburg, WI) for real-time RT-qPCR. The real-time quantitative PCRs were perfomed using a CFX96 Real-Time PCR Detection System (Bio-Rad Laboratories, Hercules, CA) and a $2 \times$ Dynamo SYBR Green qPCR kit (Thermo Fisher Scientific, Waltham, MA). The expression of genes of interest was normalized to the expression of ribosomal protein L19 (RPL19), and the expression of mRNA was quantified using the Pfaffl method. The genes analyzed by real-time RT-qPCR and sequences of the primers used are given in Table 1. 
RNA-seq analyses of vehicle $(n=15)$, enzalutamide $(n=14)$, or ARN-509 $(n=15)$ treated tumors were performed at the Finnish Microarray and Sequencing Center (Turku, Finland). The total RNA (300 ng) was used according to the Illumina TruSeq Stranded mRNA Sample Preparation Guide (Illumina, San Diego, CA). The samples were sequenced with an Illumina HiSeq 2500 instrument (Illumina) using TruSeq v3 paired-end sequencing chemistry with a 100-bp read length, combined into two lanes in the sequencing run. The quality of the RNA-seq data was investigated using the FastQC tool version 0.11.5 (Babraham Bioinformatics Group, Cambridge, UK). The reads were aligned to the human reference genome version hg19 (University of California, Santa Cruz, Santa Cruz, CA) using Tophat software version 2.0.10 (http://ccb.jhu.edu/ software/tophat/index.shtml). The number of uniquely mapped reads associated with each gene was counted using HTSeq version 0.6.1 ${ }^{21}$ with RefSeq annotations. The RNA-seq data are available from the Gene Expression Omnibus database (https://www.ncbi.nlm.nih.gov/geo; accession number GSE95413).

The downstream analysis of the data was performed using $\mathrm{R}$ version 3.2.2 (R Foundation for Statistical Computing, Vienna, Austria) and Bioconductor version 2.14 (http://bioconductor. org/install). Data were normalized for library size using the trimmed mean of M-values approach implemented in the R/ Bioconductor package edgeR. Data for statistical testing were further transformed using the voom approach in the Limma R/Bioconductor package. Pairwise comparisons between the enzalutamide-, ARN-509-, and vehicle-treated groups were performed to detect differentially expressed genes using the linear modeling approach with the empirical bayesian method in the R/Bioconductor package Limma. Genes with a false-discovery rate (Benjamini-Hochberg) adjusted $P<0.005$ and absolute fold changes $>2$ were reported for each comparison. The clustering in Supplemental Figure S1, C and D, is based on hierarchical clustering (euclidean metrics with average linkage) of the normalized count data of the differentially expressed genes. Transcript abundances of full-length ARs (AR-FLs) and AR-Vs were calculated using Salmon version 0.8.1 using a transcriptome reference file downloaded from ENSEMBL (ftp://ftp.ensembl. org/pub/release87/fasta/homo_sapiens/cdna/Homo_sapiens. GRCh38.cdna.all.fa.gz; files can be opened using WinSCP or FileZilla, free download required). (Products are not endorsed by The American Journal of Pathology.) The transcripts per million values were normalized using TMM normalization.

AR-interacting genes were selected on the basis of the gene list from the androgen receptor gene mutations database. ${ }^{22}$ The gene selection for aldo-keto reductases (AKRs), CYP enzymes, short-chain dehydrogenases/reductases, and UDP-glucuronosyltransferases (UGTs) was based on Gene Names gene family indexes. The clustering is based on hierarchical clustering (euclidean metrics with ward.2 agglomeration method, pheatmap $\mathrm{R}$ package) using the scaled mean expression value in each group.

\section{Immunoblotting}

Tumor samples were homogenized using an Ultra Turrax homogenizer (IKA-Werke) in lysis buffer containing the following: $150 \mathrm{mmol} / \mathrm{L}$ Tris- $\mathrm{HCl}, 1 \% \mathrm{NP}-40,0.5 \%$ sodium deoxycholate, $1 \mathrm{mmol} / \mathrm{L}$ EDTA, $1 \mathrm{mmol} / \mathrm{L} \mathrm{SDS}, 100 \mu \mathrm{mol} / \mathrm{L}$ sodium orthovanadate (Sigma-Aldrich), and cOmplete Mini protease inhibitor (Roche, Basel, Switzerland). Samples were centrifuged at $10,000 \times g$ for 20 minutes at $4{ }^{\circ} \mathrm{C}$, and total protein concentrations were measured with a bicinchoninic acid protein assay (Pierce, Rockford, IL). The samples were loaded onto an SDS-PAGE gel (10\% Precast Midi protein gel; Bio-Rad Laboratories) and separated under reducing conditions, followed by transfer onto an iBlot Transfer Stack membrane by an iBlot Dry Blotting System (Invitrogen). The membranes were probed with rabbit anti-AR antibody (dilution, 1:1000; sc-816; Santa Cruz Biotechnology, Dallas, TX) and an anti-AR-V7 antibody (dilution, 1:500; AG10008; Precision Antibody, Columbia, MD). For AR and AR-V7, 20 and $40 \mu \mathrm{g}$ of sample were loaded in each well, respectively. Enhanced chemiluminescence plex goat-anti-rabbit IgG-Cy5 for anti-AR (dilution, 1:2500) and anti-mouse IgG-Cy3 for AR-V7 (dilution, 1:5000) were used as secondary antibodies, and the membrane was visualized using $\mathrm{Cy} 5$ and $\mathrm{Cy} 3$ detection using a Typhoon laser scanner (GE Healthcare Life Sciences, Little Chalfont, UK).

\section{Immunohistochemistry}

Formalin-fixed, paraffin-embedded tumor samples were divided into sections before deparaffinization and rehydration. The sections were exposed to antigen retrieval in a pressure cooker in Target Retrieval Solution sodium citrate buffer (Dako, Glostrup, Denmark) for 30 minutes. The blocking reaction for nonspecific binding was followed by overnight incubation with the primary antibody against the $\mathrm{N}$-terminus of the AR (dilution, 1:250; sc-816; Santa Cruz Biotechnology) at $4^{\circ} \mathrm{C}$. Endogenous peroxidase activity was blocked via application of $1 \% \mathrm{H}_{2} \mathrm{O}_{2}$ for 20 minutes at room temperature, and the sections were incubated for 30 minutes with an anti-rabbit antibody conjugated with polymer-horseradish peroxidase (Dako), washed, and visualized with Envision + System-HRP diaminobenzidine staining (Dako). The sections were counterstained with hematoxylin, mounted, and digitized using a Pannoramic 250-slide scanner (3DHISTECH, Budapest, Hungary). The intensity of AR immunohistochemical nuclear staining was determined using CaseViewer 2.0 software including the QuantCenter and NuclearQuant modules (3DHISTECH). The nuclei were scored into three equally distributed categories: strong staining, medium staining, and weak staining (based on the range of staining intensity on the chromogen). The number of positive and negative stained cells was calculated, and the AR index was calculated by comparing the number of strong positive cells with the total number of positive cells of each section. 


\section{Measurement of Glucuronidation Activity}

Glucuronidation activity was measured using ${ }^{3} \mathrm{H}-\mathrm{DHT}$ as the substrate. For each reaction, ${ }^{3} \mathrm{H}-\mathrm{DHT}(500,000$ counts per minute/reaction) was placed into a small glass tube, evaporated under nitrogen flow, and dissolved in Tris- $\mathrm{MgCl}_{2}$ buffer ( 50 $\mathrm{mmol} / \mathrm{L}$ Tris and $10 \mathrm{mmol} / \mathrm{L} \mathrm{MgCl}_{2}$ ) supplemented with $\mathrm{L}-\alpha$ phosphatidylcholine $(100 \mu \mathrm{g} / \mathrm{mL}$; Sigma-Aldrich). Total protein $(100 \mu \mathrm{g})$ from vehicle- or antiandrogen-treated $\mathrm{VCaP}$ tumor homogenates was added to the reaction, and the final volume was adjusted with the assay buffer to $150 \mu \mathrm{L}$. Uridine 5 '-diphosphoglucuronic acid (1 mmol/L; Sigma-Aldrich), a cofactor for the reaction, was added, the samples were incubated at $37^{\circ} \mathrm{C}$ for 4 hours, and the reaction was terminated by rapid freezing. Diethyl ether (Uvasol; Merck, Darmstadt, Germany) extraction was performed to separate the free ${ }^{3} \mathrm{H}$-DHT from the ${ }^{3} \mathrm{H}$-DHT-glucuronidates present in the aqueous phase. The organic phase with ${ }^{3} \mathrm{H}$-DHT was evaporated under nitrogen flow and dissolved in $100 \mu \mathrm{L}$ ethanol. Samples were mixed with 10 $\mathrm{mL}$ Ecoscint A scintillation liquid (National Diagnostics) and measured using a Wallac 1410 liquid scintillation counter (PerkinElmer).

\section{Statistical Analysis}

Nonparametric Kruskal-Wallis and Dunn multiple comparison tests were used for steroid concentration analyses in vehicle-, enzalutamide-, or ARN-509-treated animals and for real-time RT-qPCR and RNA-seq comparisons for individual genes. Tumor/serum ratios between the treatment groups were analyzed using the Holm-Sidak multiple comparisons test. The Pearson correlation coefficient was used to compare intratumoral steroid levels and gene expression levels measured using RNA-seq. Statistics were performed using GraphPad Prism 6.0 software (GraphPad Software, San Diego, CA). The PSA growth curves were analyzed using R statistical software. The mixed-effects model, described by Laajala et $\mathrm{al}^{23}$ was used for examining differences in the linear PSA growth slope in response to antiandrogen treatments.

\section{Results}

Antiandrogen Treatment Increases the Expression of Full-Length AR and AR Splice Variants and Modulates the Expression of AR-Interacting Proteins

The CR-VCaP tumors treated with enzalutamide or ARN-509 for 4 weeks exhibited a significant response in serum PSA production with both antiandrogens, as analyzed using a matching algorithm, ${ }^{17}$ taking into account the whole treatment period (Figure 1A). However, no significant differences were observed in tumor size between the treatments arms, measured at one time point only at the end of the study period. ${ }^{16}$ Our previous study ${ }^{16}$ demonstrated that castration up-regulated the AR-FL and the expression of splice variants AR-V1 and AR-V7 in $\mathrm{VCaP}$ xenografts. The present data indicate a further increase in
AR-FL, AR-V1, and AR-V7 mRNA and protein expression after enzalutamide or ARN-509 treatment (Figure 1, B and C). AR-FL mRNA increased more than twofold, and the AR-V1 and AR-V7 variants were induced twofold to threefold compared with the castrated and vehicle-treated mice (Figure 1B); similar effects were observed using immunoblotting (Figure 1C). Immunohistochemical studies revealed that AR was localized to the nucleus in the presence of the antiandrogens (Figure 1D). However, the mRNA expression of the AR splicing factor SRSF1 and AR-V target gene $U B E 2 C$ was not significantly altered (Figure 1E). RNA-seq analyses also revealed that the expression of other genes coding for proteins involved in AR splicing were not affected (data not shown). Therefore, the mechanism by which the antiandrogens induce the expression of AR splice variants remains unknown.

Our RNA-seq analysis revealed that of 291 genes significantly up-regulated or down-regulated by one or both antiandrogens (Supplemental Figure S1A), 67 coded for AR-interacting proteins (Figure $1 \mathrm{~F}$ ). This result indicates a marked reorganization of the transcriptional machinery mediating androgen action. The down-regulated genes included TRIM68, PMEPA1, SOX9, FKBP5, and CMTM3. The expression of TFAP2C and $P R K D 1$ was up-regulated by both antiandrogens. The data also revealed a stronger effect of ARN-509 compared with enzalutamide, indicated by larger fold changes and higher number of differentially expressed genes (Figure 1F and Supplemental Figure S1).

\section{Antiandrogens Reduce Intratumoral Androgen Concentrations}

Treatment with enzalutamide or ARN-509 reduced the intratumoral $\mathrm{T}$ concentrations eightfold $(P=0.005)$ and 12-fold $(P<0.001)$, respectively, compared with vehicle-treated mice (Figure 2A). A similar decline was observed for DHT as enzalutamide- or ARN-509-treated samples presented with sevenfold $(P<0.001)$ and 12 -fold $(P<0.001)$ lower DHT concentrations (Figure 2A), respectively, compared with the vehicle-treated tumors. Androstenedione concentrations were at measureable levels but were not affected by the antiandrogen treatments (Figure 2A). We measured $3 \alpha$ - and $3 \beta$-diol levels in the tumors, but the levels were lower than the LLOD in all samples. This result indicated that the reduction in intratumoral DHT was not compensated by a comparable increase in $3 \alpha$ - and $3 \beta$-diol, which are primary downstream metabolites. Intratumoral concentrations of pregnenolone were similar in all treatment groups, but progesterone levels were significantly lower $(P=0.032)$ in enzalutamide-treated tumors than in vehicle-treated tumors (Figure 2A).

The intratumoral concentrations for all the steroids measured were higher than in serum (Figure 2B), indicating local biosynthesis. Consequently, the tumors were not the major source of the circulating androgens because the serum androgen concentrations did not follow the concentrations measured in the tumors, and antiandrogen treatment did not affect the androstenedione, $\mathrm{T}$, and DHT serum concentrations. In an additional experiment, mice 
A

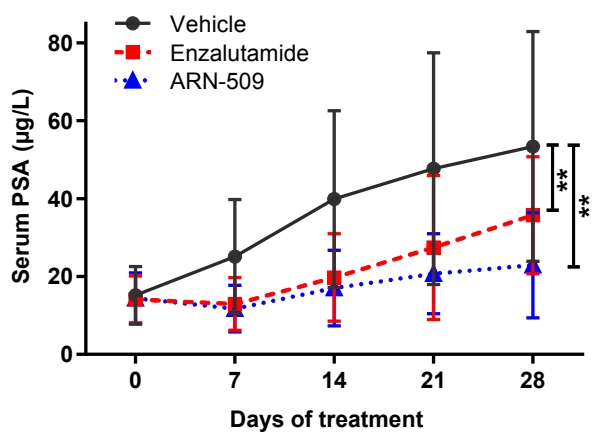

C

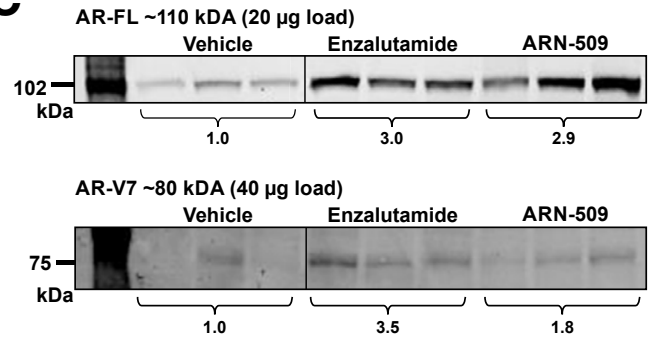

B
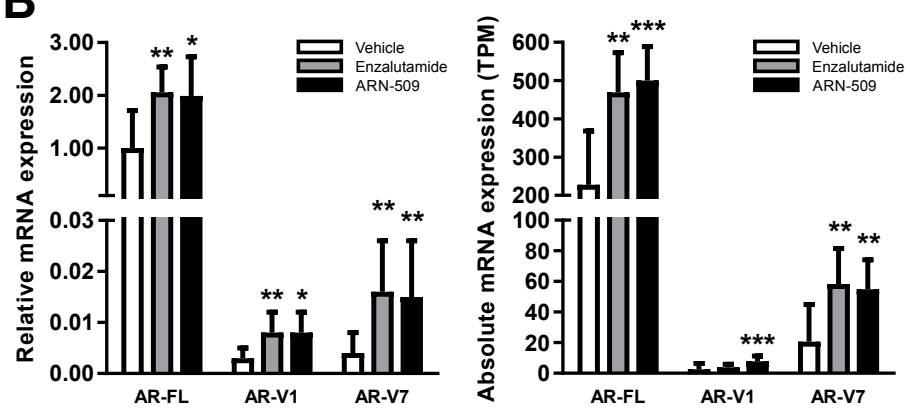

D
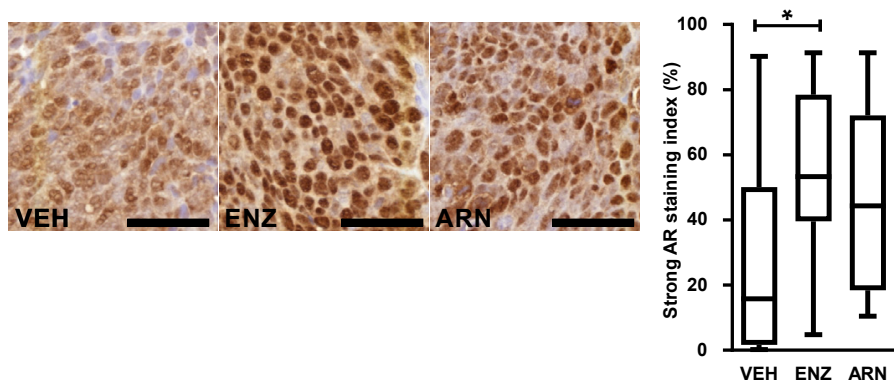

E

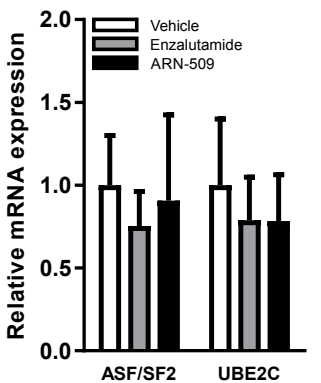

$\mathbf{F}$

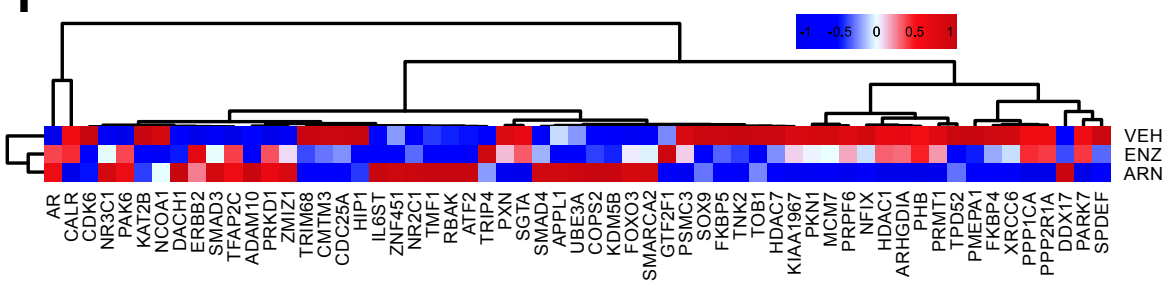

Figure 1 Antiandrogen treatment increases the expression of full-length androgen receptor (AR-FL) and AR splice variants (AR-Vs) and modulates the expression of AR-interacting proteins. A: Serum prostate-specific antigen (PSA) values measured weekly in mice carrying the orthotopic castration-resistant VCaP (CR-VCaP) tumors during the 4-week treatment with enzalutamide, ARN-509, or vehicle. B: The mRNA expression of AR-FL, AR-V1, and AR-V7 in the CRVCaP tumors after 4-week treatment with enzalutamide, ARN-509, or vehicle, presented as relative mRNA expression by real-time quantitative RT-PCR (RTqPCR), and absolute mRNA levels, measured as transcripts per million (TPM) by RNA sequencing (RNA-seq). C: Immunoblotting analysis of AR-FL and AR-V7 in CR-VCaP tumors after the 4-week treatment with enzalutamide, ARN-509, or vehicle, showing relative expression of AR-FL and AR-V7 in the tumors. D: Representative immunohistochemical staining and quantification of strong positive cell index for AR in tumors after 4-week treatment with enzalutamide (ENZ), ARN-509 (ARN), or vehicle (VEH). E: Relative expression of AR splicing factor SRSF1 (ASF/SF-2) and UBE2C mRNA after the antiandrogen treatment, analyzed by real-time RT-qPCR and normalized to ribosomal protein L19 expression. F: Heat map of the hierarchical clustering of the mRNA expression of ARinteracting proteins in VEH-, ENZ-, or ARN-treated VCaP tumors analyzed by RNA-seq. Data are expressed as means \pm SD $(\mathbf{A}, \mathbf{B}$, and $\mathbf{E}) . n=13 \mathrm{ENZ}(\mathbf{D}) ; n=14$ ARN (D); $n=15 \operatorname{VEH}$ (D). ${ }^{*} P<0.05,{ }^{* *} P<0.01$, and ${ }^{* * *} P<0.001$ versus vehicle. Scale bars $=50 \mu \mathrm{m}$ (D).

with the $\mathrm{CR}-\mathrm{VCaP}$ xenografts were treated with a single dose of enzalutamide or vehicle and were subsequently injected intraperitoneally with ${ }^{3} \mathrm{H}-\mathrm{DHT}$. A similar amount of ${ }^{3} \mathrm{H}$-DHT was observed within the antiandrogen- and vehicle-treated $\mathrm{VCaP}$ tumors, demonstrating that the presence of antiandrogen does not reduce intratumoral ${ }^{3} \mathrm{H}$-DHT concentrations in the $\mathrm{CR}-\mathrm{VCaP}$ tumors (Figure 2C). This result suggests that AR blockade by antiandrogens cannot directly cause the reduction of intratumoral $\mathrm{T}$ and DHT concentrations in the CR-VCaP tumors without altering the steroid metabolism. Intratumoral $\mathrm{T}(r=-0.6856$, $P<0.0001)$ and DHT $(r=-0.6762, P<0.0001)$ concentrations exhibited a strong negative correlation, with AR mRNA expression measured by RNA-seq (Figure 2D), suggesting that the decrease of intratumoral androgens was compensated by induced AR expression.

\section{Antiandrogens Regulate the Expression of Enzymes Involved in Androgen Biosynthesis and Metabolism}

We analyzed the expression of all CYP family enzymes and the enzymes in the families of short-chain dehydrogenases/reductases, AKRs, and UGTs in the tumors as part of the global RNA-seq analysis. Of the 258 enzymes in these families, 29 were differentially expressed between the vehicle-treated 
A
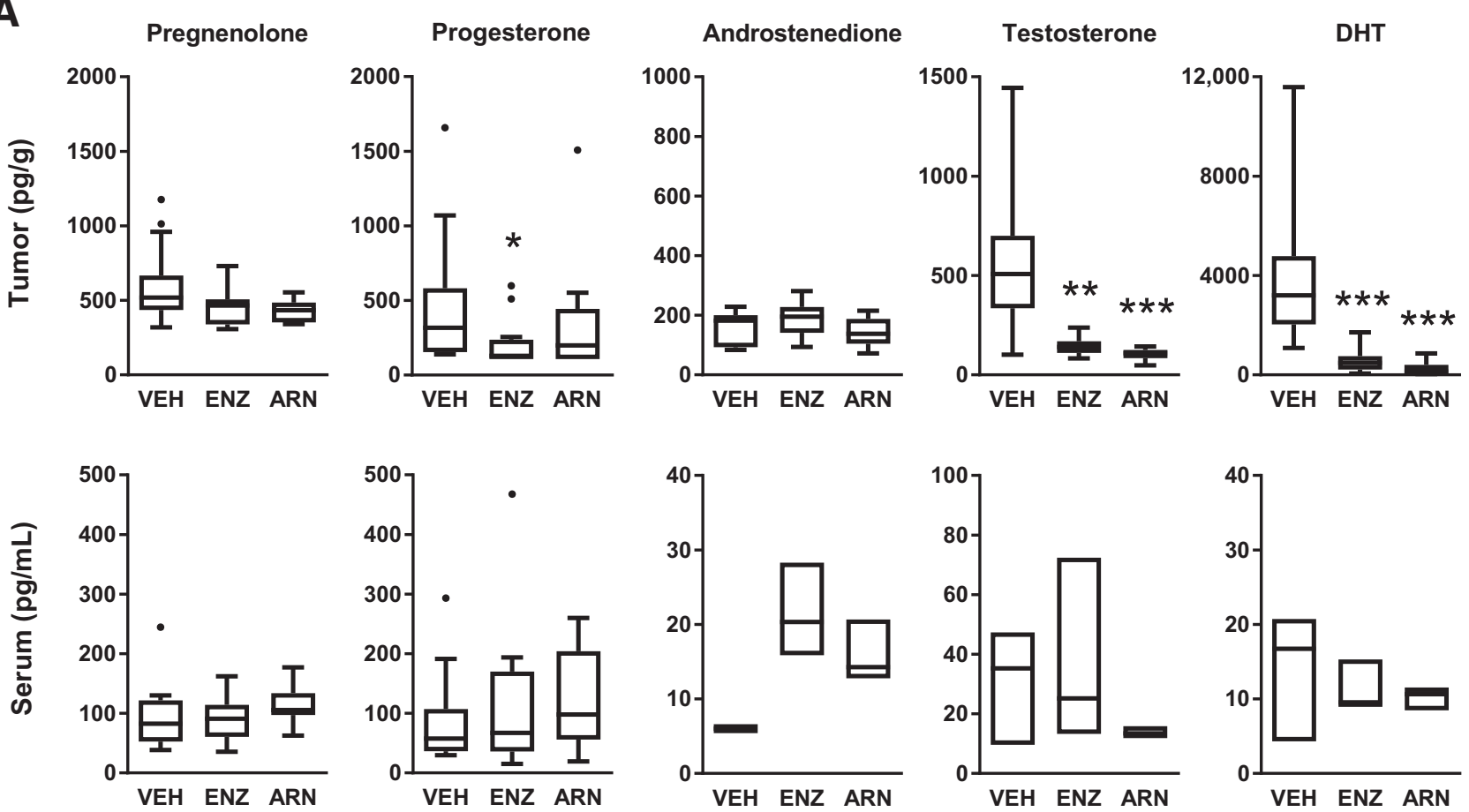

B

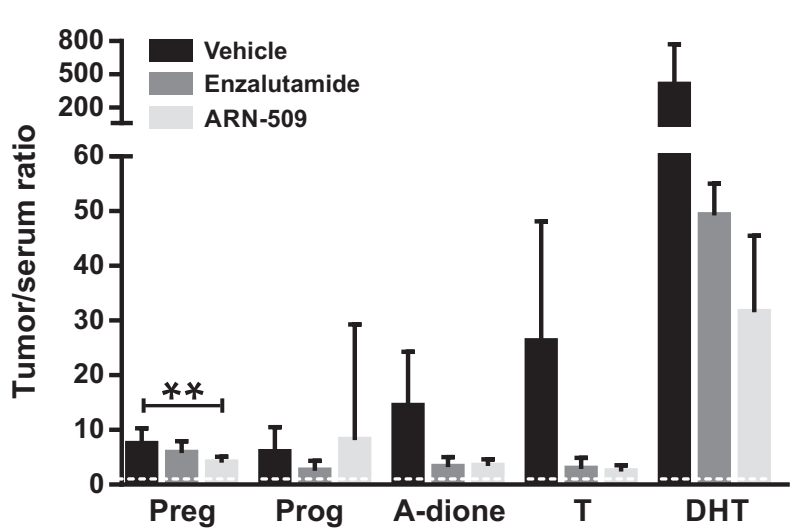

C

Intratumoral ${ }^{3} \mathrm{H}-\mathrm{DHT}$
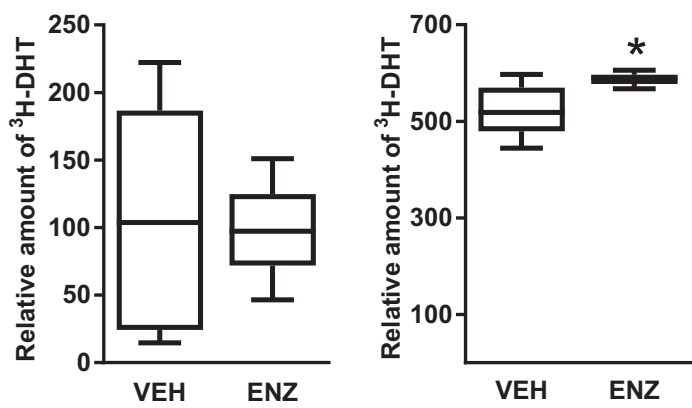

D
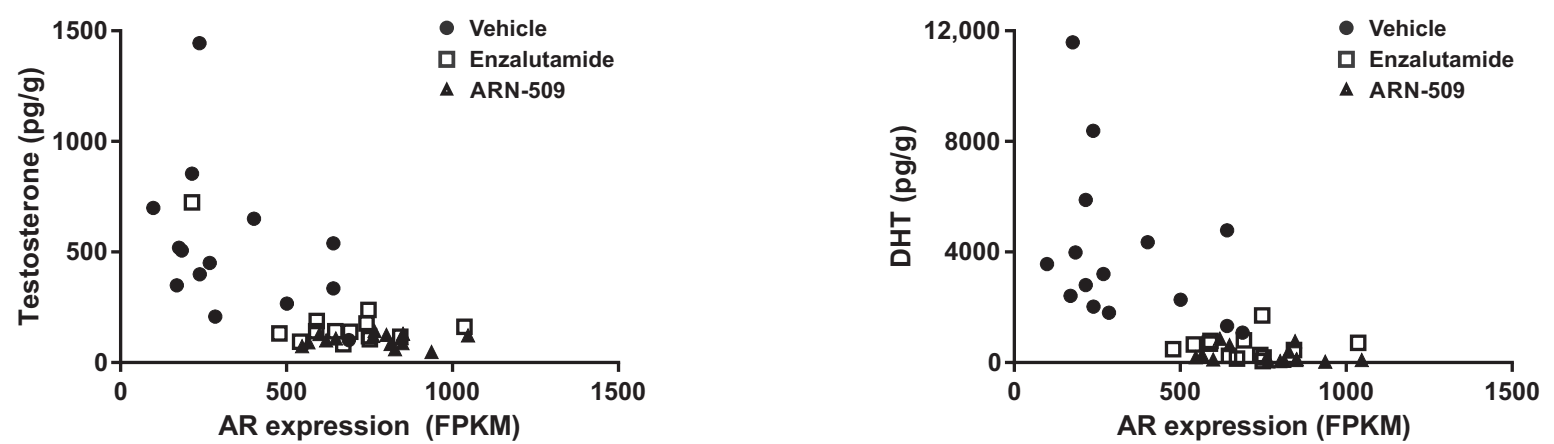

Figure 2 Antiandrogens reduce intratumoral androgen concentrations. A: Intratumoral and serum pregnenolone, progesterone, androstenedione (A-dione), testosterone $(\mathrm{T})$, and dihydrotestosterone (DHT) concentrations in vehicle (VEH), enzalutamide (ENZ), or ARN-509 (ARN) treated mice. For serum A-dione, T, and DHT measurements, serum samples from four individual mice were pooled, forming three measured serum samples for each group. B: Tumor/serum ratios of pregnenolone (Preg), progesterone (Prog), A-dione, T, and DHT in VEH-, ENZ-, or ARN-treated mice. The white dashed line indicates the tumor/serum ratio (1:1). C: Intratumoral and serum levels of ${ }^{3} \mathrm{H}-\mathrm{DHT}$ in mice with s.c. castration-resistant VCaP tumors, treated with a single dose of VEH or ENZ. D: Pearson correlation of androgen receptor (AR) mRNA expression measured using RNA sequencing and intratumoral testosterone $(r=-0.6856, P<0.0001)$ and intratumoral DHT $(r=-0.6762, P<0.0001)$ levels in VEH-, ENZ-, or ARN-treated mice. $n=15 \mathrm{VEH}$ and ARN $(\mathbf{A}, \mathbf{B}$, and $\mathbf{D}) ; n=13 \mathrm{ENZ}(\mathbf{A}, \mathbf{B}$, and $\mathbf{D}) ; n=6 \mathrm{VEH}$ and ENZ (C); $n=43$ testosterone and $\mathrm{DHT}(\mathrm{D}) .{ }^{*} P<0.05,{ }^{* *} P<0.01$, and ${ }^{* *} P<0.001$ versus vehicle. FPKM, fragments per Kb of exon per million fragments mapped. 
A
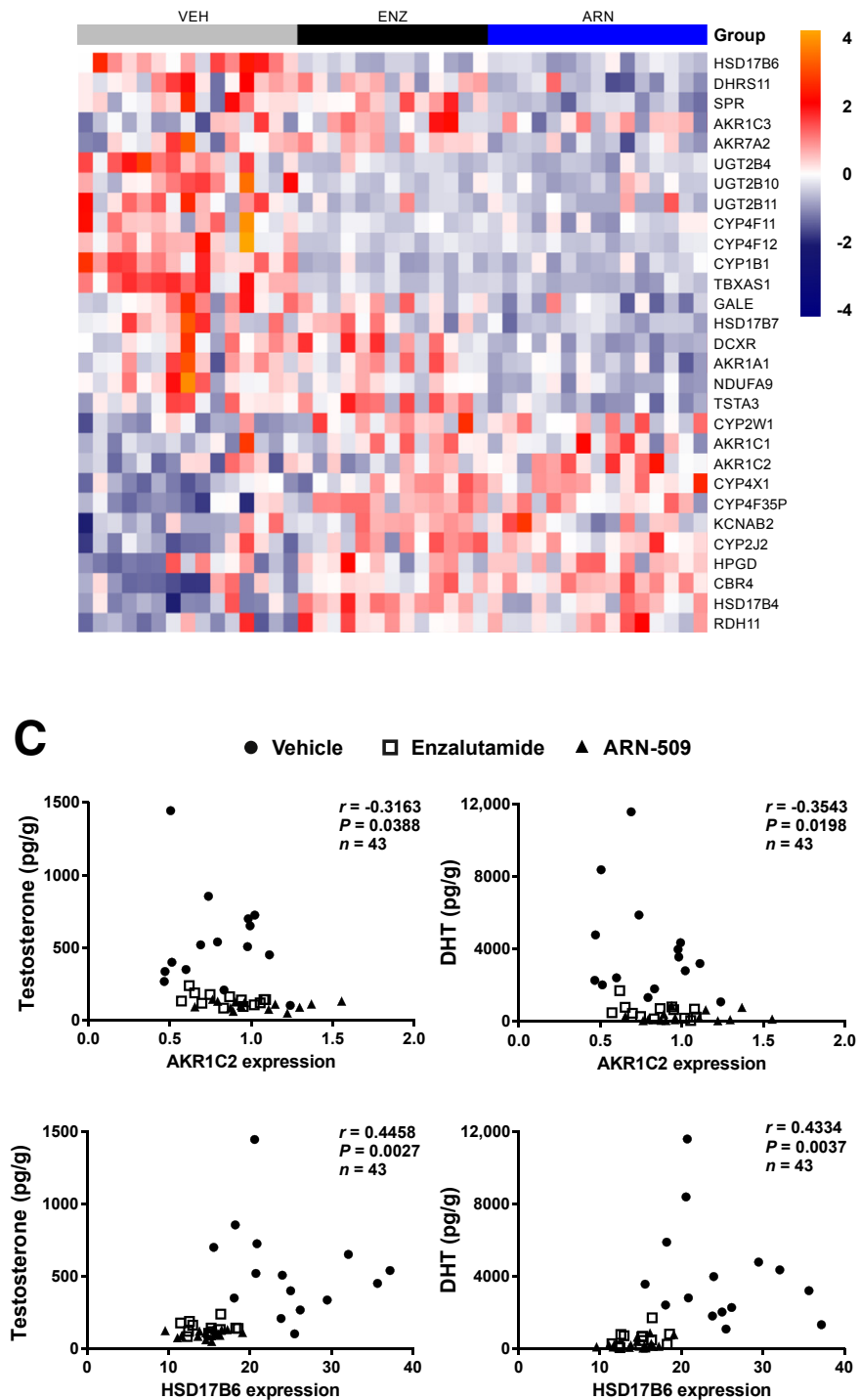

B
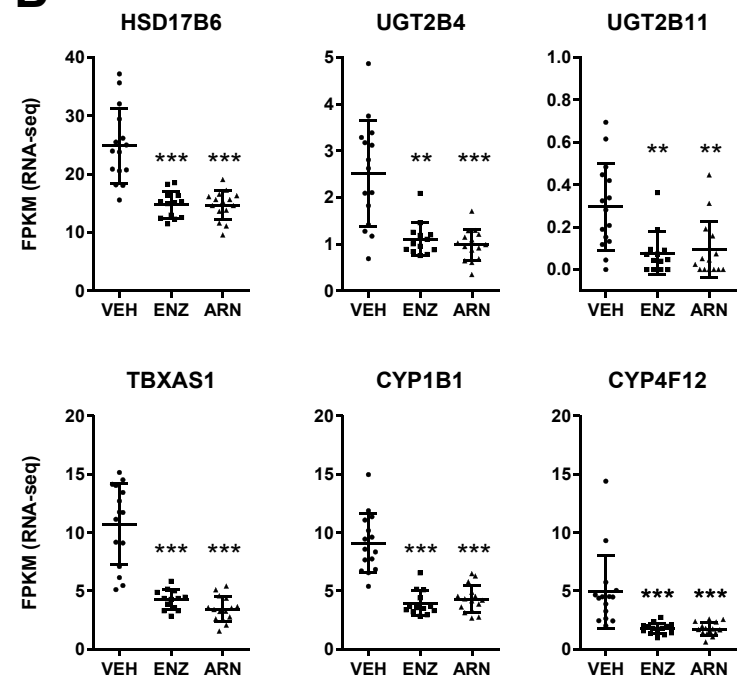

CYP4F12

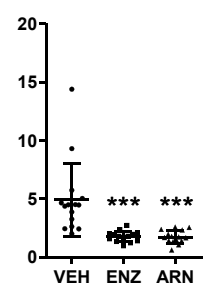

D

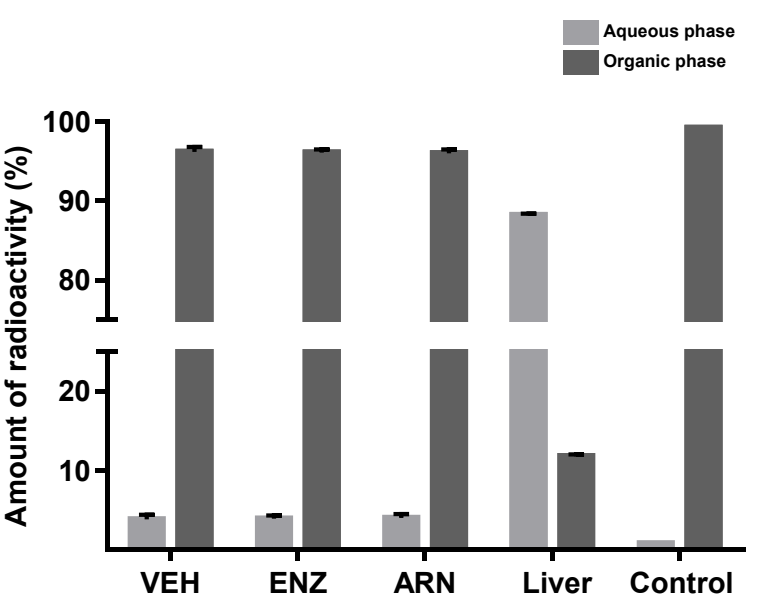

Figure 3 Antiandrogens regulate the expression of enzymes involved in androgen biosynthesis and metabolism. A: Heat map visualization of hierarchical clustering of the differently expressed enzymes of aldo-keto reductase (AKR), short-chain dehydrogenase/reductase (SDR), and cytochrome P450 (CYP) families in vehicle (VEH), enzalutamide (ENZ), or ARN-509 (ARN) treated mice, analyzed using RNA sequencing (RNA-seq) in the castration-resistant VCaP tumors. B: Examples of differently expressed mRNA levels of steroid-metabolizing enzymes (HSD17B6, UGT2B4, UGT2B11, TBXAS1, CYP1B1, and CYP4F12) after the 4-week antiandrogen treatment. C: Pearson correlation of AKR1C2 and HSD17B6 mRNA expression [fragments per Kb of exon per million fragments mapped (FPKM)] in the castration-resistant VCaP tumors and intratumoral testosterone and dihydrotestosterone (DHT) concentrations in VEH, ENZ, or ARN treated mice. D: Glucuronidation activity in the castration-resistant VCaP tumors from mice treated 4 weeks with VEH, ENZ, or ARN, measured in vitro by analyzing the radioactivity in the organic phase $\left({ }^{3} \mathrm{H}-\mathrm{DHT}\right)$ and water phase (glucuronized metabolites) after the 4-hour incubation with ${ }^{3} \mathrm{H}$-DHT in optimized conditions. Mouse liver samples were used as a positive control, and the negative controls did not contain any tissue. $n=15$ VEH and ARN $(\mathbf{A}$ and $\mathbf{C}) ; n=13$ ENZ (A and C); $n=3$ VEH, ENZ, and ARN (D). ${ }^{* \star} P<0.01,{ }^{* * * P}<0.001$ versus vehicle. UGT, UDP-glucuronosyltransferase.

tumors and either one or both antiandrogen-treated tumors (Figure 3A), several of them being potentially involved in androgen biosynthesis and metabolism. The mRNA expression of HSD17B6, TBXAS1, CYP1B1, and CYP4F12 was significantly altered by both antiandrogens (Figure 3B), but the mRNA expression of many classic androgen biosynthesis enzymes, such as HSD3B1, HSD3B2, CYP17A1, and SRD5A1, remained unchanged (data not shown). A significant negative correlation was observed between the expression of AKRIC2 and intratumoral $\mathrm{T}$ and DHT concentrations (Figure 3C), whereas a positive correlation was found between HSD17B6 expression and intratumoral $\mathrm{T}$ and DHT concentrations. UGT2B15 and UGT2B17, coding for enzymes known to conjugate $\mathrm{T}$ and DHT to corresponding glucuronide metabolites, were not differently expressed between the tumors of the antiandrogen- or vehicle-treated mice (data not shown). In line with these data, enzyme activity measurements using ${ }^{3} \mathrm{H}-\mathrm{DHT}$ as a substrate did not indicate any 
A
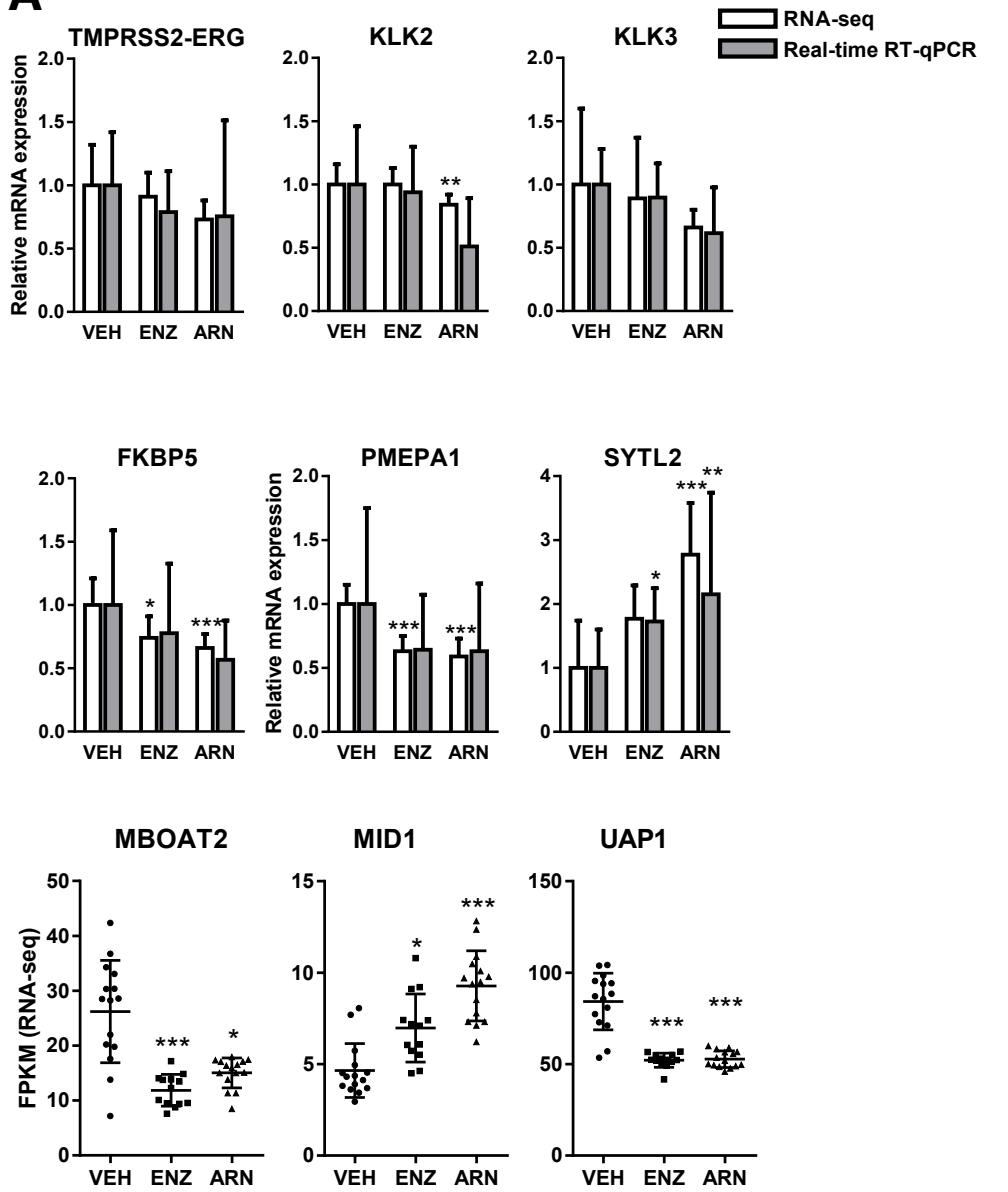

B
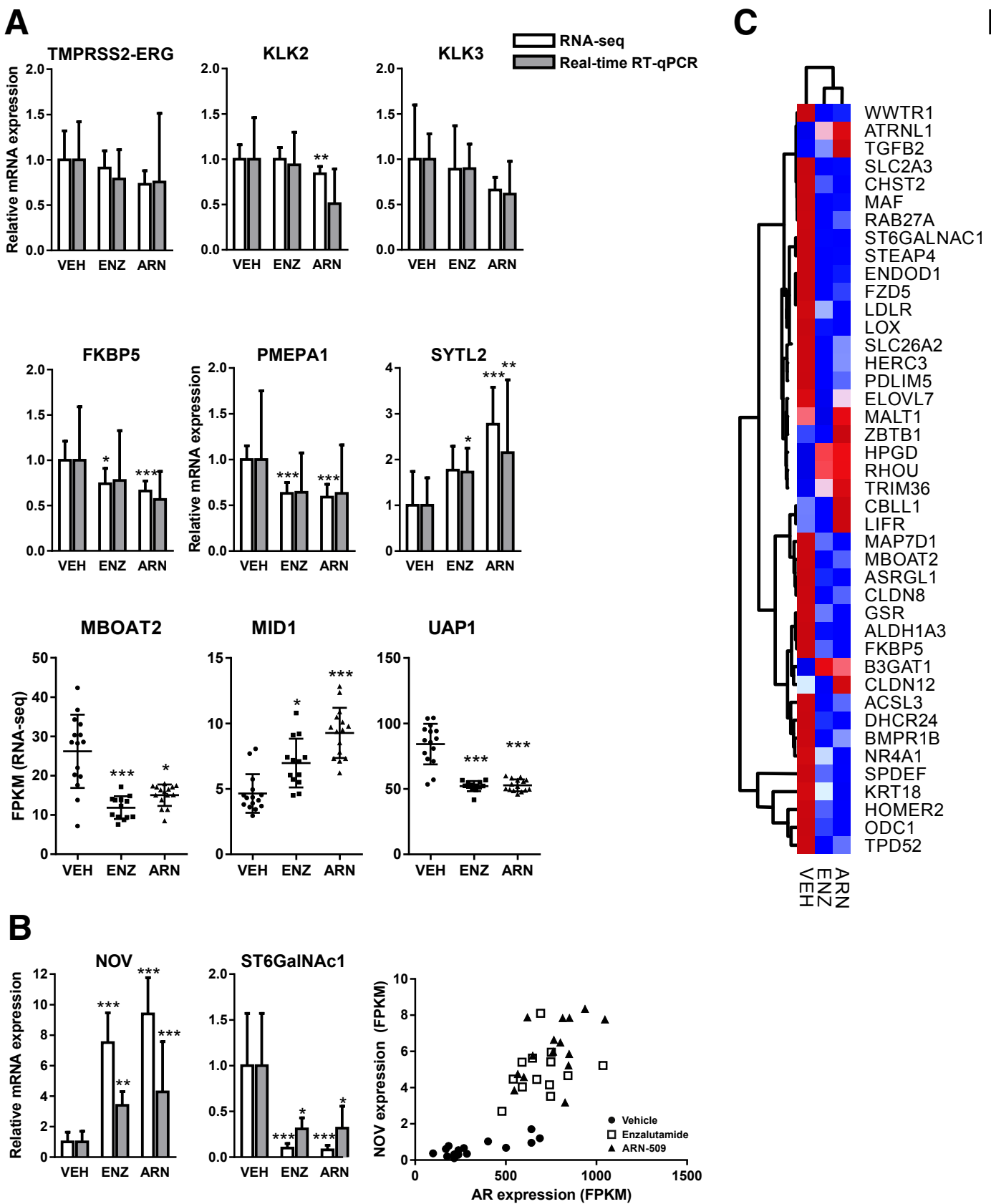

D
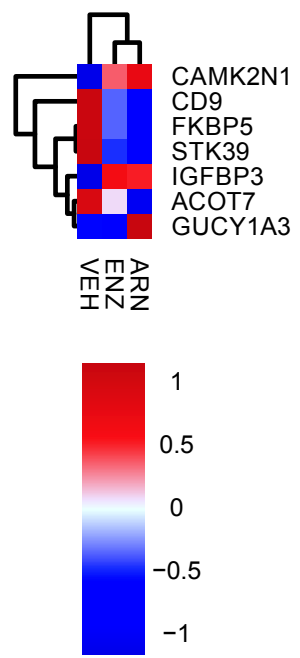

Figure 4 Antiandrogens alter the androgen-regulated gene signature. A: Relative RNA-sequencing (RNA-seq) - and real-time quantitative RT-PCR (RTqPCR)-based mRNA expression of a set of classic androgen-regulated genes (TMPRSS2-ERG, KLK2, KLK3, and FKBP5) and other androgen-regulated genes (PMEPA1, MBOAT2, MID1, SYTL2, and UAP1) in castration-resistant VCaP tumors treated with vehicle (VEH), enzalutamide (ENZ), or ARN-509 (ARN). B: The most markedly up-regulated (NOV) and down-regulated (ST6GalNaC1) genes in RNA-seq analyses in the castration-resistant VCaP tumors after 4 weeks of antiandrogen treatment, verified by real-time RT-qPCR, and the Pearson correlation between the androgen receptor (AR) and neuroblastomaoverexpressed (NOV) mRNA expression, measured by RNA-seq $(r=0.8059, P<0.0001)$. C and D: Heat map visualization of hierarchical clustering of known androgenregulated genes $(\mathbf{C})$ and known AR splice variant-regulated genes (D) in castration-resistant VCaP tumors after the 4-week treatment with VEH, ENZ, or ARN, measured using RNA-seq. $n=10 \mathrm{VEH}$, ENZ, and ARN (A), and real-time RT-qPCR (B); $n=43$ RNA-seq (B); $n=15$ VEH and ARN (C and D); $n=13$ ENZ (C and D). ${ }^{*} P<0.05,{ }^{*} P<<0.01$, and ${ }^{*} * P<0.001$ versus vehicle. FPKM, fragments per Kb of exon per million fragments mapped; ST6GalNAc1, ST6 Nacetylgalactosaminide $\alpha$-2,6-sialyltransferase 1 .

difference in the total glucuronidation activity in the tumors of antiandrogen- or vehicle-treated mice (Figure 3D). However, several enzymes of the UGT2B family, capable of forming the polar steroid-glucuronides, such as UGT2B4 and $U G T 2 B 11$, were down-regulated by both antiandrogens
(Figure 3, A and B). Therefore, the antiandrogen treatments result in a major alteration in the steroid biosynthesis machinery in the castration-resistant tumors; however, the exact pathway leading to reduced androgen concentration remains unclear. 
Antiandrogens Alter Androgen-Regulated Gene Signature

Our previous study observed that castration transiently decreased the expression of androgen-regulated genes, but eventually the expression of several classic AR target genes was restored to precastration levels in CR-VCaP tumors. ${ }^{16}$ Hierarchical clustering revealed similar expression patterns for the androgen-regulated genes before and after castration. The principal component analysis and hierarchical clustering of the RNA-seq data of the known androgen-regulated genes revealed a clear separation of the vehicle- and antiandrogen-treated tumors (Supplemental Figure S1, B-D), indicating the presence of AR signaling in the castration-resistant $\mathrm{VCaP}$ xenografts. Furthermore, the RNA-seq data and real-time RT-qPCR analyses (Figure 4) indicate variable antiandrogen responses for the androgen-regulated genes, suggesting differential mechanisms of their regulation and/or differential androgen sensitivities for their expression. No change (TMPRSS2 and KLK3) or significant change (KLK2, FKBP5, MBOAT2, MID1, SYTL2, $P M E P A 1$, and $U A P 1$ ) was observed in the gene expression of several known androgen-regulated genes (Figure 4, A and C). However, the expression of several known AR-V target genes, including ACOT7, CAMK2N1, GUCY1A3, IGFBP3, neuroblastoma overexpressed (NOV), ST6 N-acetylgalactosaminide $\alpha$-2,6-sialyltransferase 1 (ST6GalNAc1), and STK39, was altered in antiandrogen-treated tumors (Figure 4, B and D). Supplemental Tables S1-S4 present the genes with most markedly altered mRNA expression after antiandrogen treatment. The most down-regulated genes included leucine zipper protein 2 (LUZP2), STEAP4 metalloreductase (STEAP4), and ST6GalNAc1, indicating a beneficial antiproliferative effect of the antiandrogen treatments. The most prominently up-regulated (NOV) and down-regulated (ST6GalNAcl) genes (Figure 4C) represent novel biomarkers for determining the efficacy of antiandrogen treatment.

\section{Discussion}

Current hormonal therapies of CRPC are focused on the blockade of AR signaling because of the high AR expression ${ }^{4}$ and the presence of intratumoral androgen biosynthesis ${ }^{24}$ in the tumors. However, in addition to the ligand-activated fulllength AR, CRPC also expresses constitutively active AR splice variants lacking the ligand-binding domain, ${ }^{25}$ providing the possibility for androgen-independent actions of AR in CRPC. However, the mechanisms of the androgen-dependent growth of CRPC are still unclear.

In the present study, we analyzed the effects of antiandrogens (enzalutamide and ARN-509) on the castration-resistant o.t. $\mathrm{VCaP}$ tumors grown in immunodeficient mice. This preclinical model shares key features analogous to clinical CRPC. Namely, after the removal of circulating androgens by castration, the CR$\mathrm{VCaP}$ tumors reappear and present with high expression of fulllength $\mathrm{AR}$ and express AR splice variants, ${ }^{16}$ and the tumors grown in castrated mice show activation of intratumoral androgen biosynthesis. ${ }^{16}$ The present study demonstrated that antiandrogen treatment of the $\mathrm{CR}-\mathrm{VCaP}$ tumors further induced the expression of AR-FL and the splice variants AR-V1 and ARV7. The data also translate into clinical findings because the expression of AR-FL and AR splice variants is up-regulated in CRPC patients treated with enzalutamide. ${ }^{26}$ The levels of the AR splice variants were, however, modest in the CR-VCaP tumors both before and after antiandrogen treatment. Thus, the full-length AR-mediated signaling likely predominates over the splice variants in the CR-VCaP tumors.

Previous studies with clinical specimens have evidently established that CRPC tumors present with intratumoral biosynthesis of androgens ${ }^{27-29}$ and retain intratumoral androgens after androgen deprivation therapy. ${ }^{30-32}$ The CR-VCaP tumors are alike, and we have demonstrated previously that $\mathrm{CR}-\mathrm{VCaP}$ xenografts presented with precastration levels of T and DHT after a transient reduction after castration. ${ }^{16}$ The present study also demonstrated that a 4-week-long treatment with antiandrogens significantly reduced intratumoral $\mathrm{T}$ and DHT levels in the CR-VCaP xenografts. A similar observation was recently demonstrated for clinical CRPC because the treatment with luteinizing hormone-releasing hormone agonist together with bicalutamide was associated with lower intratumoral DHT levels compared with the tumors from patients treated with the luteinizing hormone-releasing hormone agonist alone. ${ }^{33}$ In contrast to our study with $\mathrm{VCaP}$ xenografts, no difference in the intratumoral testosterone concentrations was identified in the tumors of luteinizing hormone-releasing hormone agonist-treated patients with or without bicalutamide. ${ }^{33}$ However, it is possible that the assay used in the study was not sensitive enough to reliably detect the potential differences between the low testosterone concentrations in these tumors. Taken together, the CRPC tumors in patients and VCaP xenografts in castrated mice respond similarly to antiandrogens by increasing the expression of AR and reducing intratumoral androgens levels. These results indicate that, in addition to blocking the binding of active androgens to AR, the reduction in intratumoral androgens is a novel mechanism by which antiandrogens mediate their known antiproliferative effects in CRPC.

The present study demonstrates that the intratumoral levels of active androgens in the $\mathrm{VCaP}$ xenografts are higher compared with serum levels with and without antiandrogen treatment. This result indicates local production of androgens, and the reduced androgen levels in antiandrogen-treated tumors may result from the direct or indirect regulation of the activity and/or expression of enzymes responsible for biosynthesis and metabolism of the androgens within the tumors. In line with this, several experiments were performed to examine the mechanisms by which the antiandrogen treatment led to reduced androgen concentrations in the CR-VCaP tumors. The concentrations of the downstream DHT metabolites $3 \alpha$ - and $3 \beta$-diol were measured in the tumors, showing that the decline in DHT concentration was not associated with a corresponding increase in these metabolites. However, the relatively high LLOD of the assay precluded 
detection of minor changes in the concentration of these metabolites.

The reduction of active androgens in the CR-VCaP tumors may have been caused by increased glucuronidation of androgens into water-soluble conjugates. However, neither measurement of the enzymatic activity nor the RNA expression analyses of the UDP-glucuronosyltransferases provided evidence for an increased glucuronidation in the tumors. Instead, some of the enzymes potentially involved in steroid conjugation, such as UGT2B4 $4^{34}$ and UGT2B11, were down-regulated in the antiandrogen-treated tumors. The roles of UGT2B15 and UGT2B17 in androgen metabolism in the prostate has been demonstrated previously, ${ }^{3,36}$ yet the expression of these two enzymes or the key enzymes related to the formation of steroid sulfates (STS and SULTS) was not altered on the basis of the RNA-seq analyses. Furthermore, no difference was found in the expression of transporters $(A B C C 1, L R P 2, S L C O 1 A 2$, $S L C O 1 B 1, S L C O 1 B 3$, and $S L C O 2 B 1)$ suggested to be involved in steroid transport in peripheral tissues. ${ }^{37}$ Although the exact mechanism that resulted in the reduced intratumoral androgens levels remains unclear, the antiandrogen treatment altered the expression of several steroidogenic enzymes associated with local androgen production, ${ }^{38,39}$ including $A K R 1 C 2, A K R 1 C 3$, and $H S D 17 B 6$. The antiandrogen treatment also altered the expression of several AKR, CYP, and short-chain dehydrogenase/reductase enzymes whose role in steroid metabolism is not known. Their possible impact in androgen metabolism is supported by the fact that novel steroid metabolic enzymes are continuously being discovered, with human dehydrogenase/reductase member 11 (DHRS11) being a recent example. ${ }^{40}$

Although the expression of several androgen-regulated genes and AR-interacting proteins was significantly altered, the antiandrogens had only a modest effect on the expression of certain classic androgen-regulated genes, such as TMPRSS2, KLK2, and $K L K 3$, suggesting that a certain amount of androgen action remained in the antiandrogentreated tumors. The conditions at a molecular level are complex, with the presence of a high amount of AR and antiandrogen, together with low levels of ligandindependent forms of AR and other steroidal ligands, such as progestins. Androgen-regulated genes present with a differential response in this setting, and the final biological response is a combination of several mechanisms. One possibility is that AR splice variants drive at least a part of the remaining androgen target gene expression. Several studies have revealed that AR splice variants lacking the ligand-binding domain activate certain target genes typically activated by AR-FL in the presence of a ligand, ${ }^{12,41,42}$ whereas other studies have indicated that AR splice variants possess a transcriptional AR signature distinct from AR-FL. ${ }^{43,44}$ For example, FKBP5 mRNA levels were suggested to mirror the androgen concentrations and reflect the ligand-dependent androgen action in human prostate better than other classic AR target genes, such as $K L K 3$ (PSA). ${ }^{32}$ However, in the present study, FKBP5 was not a sensitive marker for the altered androgen action in the antiandrogentreated CR-VCaP tumors, but RNA-seq data revealed other genes whose expression was highly sensitive to the changes induced by the antiandrogen treatments. Some of these genes were recently observed to be androgen regulated by others; however, the direct androgen dependency of some of the highly antiandrogen-regulated genes must be further characterized. In addition to testosterone and DHT, other physiologically important androgens also exist. ${ }^{45}$ Among those, the potential roles of 11-ketotestosterone and 11-ketoDHT need to be studied in the present model and in CRPC in general, because 11-keto-DHT exhibits properties similar to DHT. ${ }^{46}$ Furthermore, the possibility of AR activation by intratumoral progestins must be considered in our future studies. $^{47}$

The most up-regulated $(N O V)$ and down-regulated (ST6GalNAc1) genes in our RNA-seq data represent novel, recently identified, androgen-dependent genes. AR directly suppress $N O V$ expression in $\mathrm{VCaP}$ cells grown in vitro by binding to the promoter and enhancer regions of $N O V$, whereas NOV expression is induced by ADT in mice and prostate cancer patients. ${ }^{48}$ This observation, together with our results demonstrating that NOV expression is decreased by antiandrogen treatment, indicates that $N O V$ is a sensitive marker for antiandrogen action both in vitro and in vivo. ST6GalNAc1, a sialyltransferase involved in the modification of the carbohydrate moieties of proteins, was recently identified to be regulated by androgens in prostate cancer, ${ }^{49}$ which is consistent with our results showing a strong 10-fold down-regulation of ST6GalNAc1. Further studies are needed to reveal the role of these proteins in the androgen response. However, because of the high similarity in the androgen responsiveness between clinical CRPC and CR-VCaP tumors, the present study indicates that analyzing the expression of ST6GalNAcl (down-regulation) and NOV (up-regulation) mRNA would be a useful tool to determine the efficacy of antiandrogen treatment also in clinical CRPC.

In summary, our data indicate that the CR-VCaP xenografts present with features similar to clinical CRPC, with induced AR expression and reduced amount of intratumoral androgens as a response to antiandrogen treatment. We identified two sensitive markers for antiandrogen action, ST6GalNAcl and NOV, whose usefulness in determining the efficacy of antiandrogen action in clinical CRPC remains to be confirmed.

\section{Acknowledgments}

We thank the personnel working at the Department of Physiology and at the Turku Center for Disease Modeling (University of Turku, Turku, Finland); Jenni Mäki-Jouppila, Nina Messner, Heli Niittymäki, Katri Hovirinta, Taina 
Kirjonen, Mona Niiranen, Anu Salminen, and Saana Viertomanner for technical assistance; the staff at Orion Pharma for collaboration; and Kim Pettersson (University of Turku) for providing reagents for the prostate-specific antigen assay.

\section{Supplemental Data}

Supplemental material for this article can be found at https://doi.org/10.1016/j.ajpath.2017.08.036.

\section{References}

1. Torre LA, Siegel RL, Ward EM, Jemal A: Global cancer incidence and mortality rates and trends: an update. Cancer Epidemiol Biomarkers Prev 2016, 25:16-27

2. Heidenreich A, Bastian PJ, Bellmunt J, Bolla M, Joniau S, Van Der Kwast T, Mason M, Matveev V, Wiegel T, Zattoni F, Mottet N: EAU guidelines on prostate cancer, part II: treatment of advanced, relapsing, and castration-resistant prostate cancer. Eur Urol 2014, 65:467-479

3. Slovin SF, Wilton AS, Heller G, Scher HI: Time to detectable metastatic disease in patients with rising prostate-specific antigen values following surgery or radiation therapy. Clin Cancer Res 2005, 11:8669-8673

4. Yuan X, Cai C, Chen S, Yu Z, Balk SP: Androgen receptor functions in castration-resistant prostate cancer and mechanisms of resistance to new agents targeting the androgen axis. Oncogene 2014, 33:2815-2825

5. Cai C, Balk SP: Intratumoral androgen biosynthesis in prostate cancer pathogenesis and response to therapy. Endocr Relat Cancer 2011, 18: R175-R182

6. Clegg NJ, Wongvipat J, Joseph JD, Tran C, Ouk S, Dilhas A, Chen Y, Grillot K, Bischoff ED, Cai L, Aparicio A, Dorow S, Arora V, Shao G, Qian J, Zhao H, Yang G, Cao C, Sensintaffar J, Wasielewska T, Herbert MR, Bonnefous C, Darimont B, Scher HI, Smith-Jones P, Klang M, Smith ND, De Stanchina E, Wu N, Ouerfelli O, Rix PJ, Heyman RA, Jung ME, Sawyers CL, Hager JH: ARN-509: a novel antiandrogen for prostate cancer treatment. Cancer Res 2012, 72: 1494-1503

7. Moilanen A-M, Riikonen R, Oksala R, Ravanti L, Aho E, Wohlfahrt G, Nykänen PS, Törmäkangas OP, Palvimo JJ, Kallio PJ: Discovery of ODM-201, a new-generation androgen receptor inhibitor targeting resistance mechanisms to androgen signaling-directed prostate cancer therapies. Sci Rep 2015, 5:12007

8. Tran C, Ouk S, Clegg NJ, Chen Y, Watson PA, Arora V, Wongvipat J, Smith-Jones PM, Yoo D, Kwon A, Wasielewska T, Welsbie D, Chen CD, Higano CS, Beer TM, Hung DT, Scher HI, Jung ME, Sawyers CL: Development of a second-generation antiandrogen for treatment of advanced prostate cancer. Science 2009, 324:787-790

9. Visakorpi T, Hyytinen E, Koivisto P, Tanner M, Keinänen R, Palmberg C, Palotie A, Tammela T, Isola J, Kallioniemi OP: In vivo amplification of the androgen receptor gene and progression of human prostate cancer. Nat Genet 1995, 9:401-406

10. Zhang X, Morrissey C, Sun S, Ketchandji M, Nelson PS, True LD, Vakar-Lopez F, Vessella RL, Plymate SR: Androgen receptor variants occur frequently in castration resistant prostate cancer metastases. PLoS One 2011, 6:e27970

11. Hu R, Dunn TA, Wei S, Isharwal S, Veltri RW, Humphreys E, Han M, Partin AW, Vessella RL, Isaacs WB, Bova GS, Luo J: Ligand-independent androgen receptor variants derived from splicing of cryptic exons signify hormone-refractory prostate cancer. Cancer Res 2009, 69:16-22

12. Guo Z, Yang X, Sun F, Jiang R, Linn DE, Chen H, Chen H, Kong X, Melamed J, Tepper CG, Kung H-J, Brodie AMH, Edwards J, Qiu Y: A novel androgen receptor splice variant is up-regulated during prostate cancer progression and promotes androgen depletion-resistant growth. Cancer Res 2009, 69:2305-2313
13. Korenchuk S, Lehr JE, MClean L, Lee YG, Whitney S, Vessella R, Lin DL, Pienta KJ: VCaP, a cell-based model system of human prostate cancer. In Vivo 2001, 15:163-168

14. Cai C, Wang H, Xu Y, Chen S, Balk SP: Reactivation of androgen receptor-regulated TMPRSS2:ERG gene expression in castrationresistant prostate cancer. Cancer Res 2009, 69:6027-6032

15. Cai C, Chen S, Ng P, Bubley GJ, Nelson PS, Mostaghel EA, Marck B, Matsumoto AM, Simon NI, Wang H, Balk SP: Intratumoral de novo steroid synthesis activates androgen receptor in castration-resistant prostate cancer and is upregulated by treatment with CYP17A1 inhibitors. Cancer Res 2011, 71:6503-6513

16. Knuuttila M, Yatkin E, Kallio J, Savolainen S, Laajala TD, Aittokallio T, Oksala R, Häkkinen M, Keski-Rahkonen P, Auriola S, Poutanen M, Mäkelä S: Castration induces up-regulation of intratumoral androgen biosynthesis and androgen receptor expression in an orthotopic VCaP human prostate cancer xenograft model. Am J Pathol 2014, 184:2163-2173

17. Laajala TD, Jumppanen M, Huhtaniemi R, Fey V, Kaur A, Knuuttila M, Aho E, Oksala R, Westermarck J, Mäkelä S, Poutanen M, Aittokallio T: Optimized design and analysis of preclinical intervention studies in vivo. Sci Rep 2016, 6:30723

18. Nilsson ME, Vandenput L, Tivesten Å, Norlén A-K, Lagerquist MK, Windahl SH, Börjesson AE, Farman HH, Poutanen M, Benrick A, Maliqueo M, Stener-Victorin E, Ryberg H, Ohlsson C: Measurement of a comprehensive sex steroid profile in rodent serum by highsensitive gas chromatography-tandem mass spectrometry. Endocrinology 2015, 156:2492-2502

19. Keski-Rahkonen P, Huhtinen K, Poutanen M, Auriola S: Fast and sensitive liquid chromatography-mass spectrometry assay for seven androgenic and progestagenic steroids in human serum. J Steroid Biochem Mol Biol 2011, 127:396-404

20. McNamara KM, Harwood DT, Simanainen U, Walters KA, Jimenez M, Handelsman DJ: Measurement of sex steroids in murine blood and reproductive tissues by liquid chromatography-tandem mass spectrometry. J Steroid Biochem Mol Biol 2010, 121:611-618

21. Anders S, Pyl PT, Huber W: HTSeq: a Python framework to work with high-throughput sequencing data. Bioinformatics 2014, 31:166-169

22. Gottlieb B, Beitel LK, Nadarajah A, Paliouras M, Trifiro M: The androgen receptor gene mutations database: 2012 update. Hum Mutat 2012, 33:887-894

23. Laajala TD, Corander J, Saarinen NM, Mäkelä K, Savolainen S, Suominen MI, Alhoniemi E, Mäkelä S, Poutanen M, Aittokallio T: Improved statistical modeling of tumor growth and treatment effect in preclinical animal studies with highly heterogeneous responses in vivo. Clin Cancer Res 2012, 18:4385-4396

24. Zhang A, Zhang J, Plymate S, Mostaghel EA: Classical and nonclassical roles for pre-receptor control of DHT metabolism in prostate cancer progression. Horm Cancer 2016, 7:104-113

25. Lu J, Van der Steen T, Tindall DJ: Are androgen receptor variants a substitute for the full-length receptor? Nat Rev Urol 2015, 12:137-144

26. Antonarakis ES, Lu C, Wang H, Luber B, Nakazawa M, Roeser JC, Chen Y, Mohammad TA, Chen Y, Fedor HL, Lotan TL, Zheng Q, De Marzo AM, Isaacs JT, Isaacs WB, Nadal R, Paller CJ, Denmeade SR, Carducci MA, Eisenberger MA, Luo J: AR-V7 and resistance to enzalutamide and abiraterone in prostate cancer. N Engl J Med 2014, 371: $1028-1038$

27. Montgomery RB, Mostaghel EA, Vessella R, Hess DL, Kalhorn TF, Higano CS, True LD, Nelson PS: Maintenance of intratumoral androgens in metastatic prostate cancer: a mechanism for castrationresistant tumor growth. Cancer Res 2008, 68:4447-4454

28. Stanbrough M, Bubley GJ, Ross K, Golub TR, Rubin MA, Penning TM, Febbo PG, Balk SP: Increased expression of genes converting adrenal androgens to testosterone in androgen-independent prostate cancer. Cancer Res 2006, 66:2815-2825

29. Locke JA, Guns ES, Lubik AA, Adomat HH, Hendy SC, Wood CA, Ettinger SL, Gleave ME, Nelson CC: Androgen levels increase by intratumoral de novo steroidogenesis during progression of castrationresistant prostate cancer. Cancer Res 2008, 68:6407-6415 
30. Mizokami A, Koh E, Fujita H, Maeda Y, Egawa M, Koshida K: The adrenal androgen androstenediol is present in prostate cancer tissue after androgen deprivation therapy and activates mutated androgen receptor. Cancer Res 2004, 64:765-771

31. Page ST, Lin DW, Mostaghel EA, Hess DL, True LD, Amory JK, Nelson PS, Matsumoto AM, Bremner WJ: Persistent intraprostatic androgen concentrations after medical castration in healthy men. J Clin Endocrinol Metab 2006, 91:3850-3856

32. Mostaghel EA, Page ST, Lin DW, Fazli L, Coleman IM, True LD, Knudsen B, Hess DL, Nelson CC, Matsumoto AM, Bremner WJ, Gleave ME, Nelson PS: Intraprostatic androgens and androgenregulated gene expression persist after testosterone suppression: therapeutic implications for castration-resistant prostate cancer. Cancer Res 2007, 67:5033-5041

33. Sayyid R, Evans A, Hersey K, Maloni R, Hurtado-Coll A, Kulkarni G, Finelli A, Zlotta AR, Hamilton R, Gleave M, Fleshner N: A phase II, randomized, open label study of neoadjuvant degarelix versus LHRH agonist in prostate cancer patients prior to radical prostatectomy. Clin Cancer Res 2017, 23:1974-1980

34. Lévesque E, Beaulieu M, Hum DW, Bélanger A: Characterization and substrate specificity of UGT2B4 (E458): a UDP-glucuronosyltransferase encoded by a polymorphic gene. Pharmacogenetics 1999, 9:207-216

35. Grosse L, Pâquet S, Caron P, Fazli L, Rennie PS, Bélanger A, Barbier O: Androgen glucuronidation: an unexpected target for androgen deprivation therapy, with prognosis and diagnostic implications. Cancer Res 2013, 73:6963-6971

36. Chouinard S, Barbier O, Bélanger A: UDP-glucuronosyltransferase 2B15 (UGT2B15) and UGT2B17 enzymes are major determinants of the androgen response in prostate cancer LNCaP cells. J Biol Chem 2007, 282:33466-33474

37. Cho E, Montgomery RB, Mostaghel EA: Minireview: SLCO and ABC transporters: a role for steroid transport in prostate cancer progression. Endocrinology 2014, 155:4124-4132

38. Bauman DR, Steckelbroeck S, Williams MV, Peehl DM, Penning TM: Identification of the major oxidative $3 \alpha$-hydroxysteroid dehydrogenase in human prostate that converts $5 \alpha$-androstane- $3 \alpha, 17 \beta$-diol to $5 \alpha$ dihydrotestosterone: a potential therapeutic target for androgendependent disease. Mol Endocrinol 2006, 20:444-458

39. Ishizaki F, Nishiyama $T$, Kawasaki $T$, Miyashiro $Y$, Hara N, Takizawa I, Naito M, Takahashi K: Androgen deprivation promotes intratumoral synthesis of dihydrotestosterone from androgen metabolites in prostate cancer. Sci Rep 2013, 3:1528
40. Endo S, Miyagi N, Matsunaga T, Hara A, Ikari A: Human dehydrogenase/reductase (SDR family) member 11 is a novel type of $17 \beta$ hydroxysteroid dehydrogenase. Biochem Biophys Res Commun 2016 , 472:231-236

41. Watson PA, Chen YF, Balbas MD, Wongvipat J, Socci ND, Viale A, Kim K, Sawyers CL: Constitutively active androgen receptor splice variants expressed in castration-resistant prostate cancer require fulllength androgen receptor. Proc Natl Acad Sci U S A 2010, 107: $16759-16765$

42. Hu R, Isaacs WB, Luo J: A snapshot of the expression signature of androgen receptor splicing variants and their distinctive transcriptional activities. Prostate 2011, 71:1656-1667

43. Hu R, Lu C, Mostaghel EA, Yegnasubramanian S, Gurel M, Tannahill C, Edwards J, Isaacs WB, Nelson PS, Bluemn E, Plymate SR, Luo J: Distinct transcriptional programs mediated by the liganddependent full-length androgen receptor and its splice variants in castration-resistant prostate cancer. Cancer Res 2012, 72:3457-3462

44. Lu J, Lonergan PE, Nacusi LP, Wang L, Schmidt LJ, Sun Z, Van der Steen T, Boorjian SA, Kosari F, Vasmatzis G, Klee GG, Balk SP, Huang $\mathrm{H}$, Wang C, Tindall DJ: The cistrome and gene signature of androgen receptor splice variants in castration resistant prostate cancer cells. J Urol 2015, 193:690-698

45. Pretorius E, Arlt W, Storbeck KH: A new dawn for androgens: novel lessons from 11-oxygenated C19 steroids. Mol Cell Endocrinol 2017. 441:76-85

46. Storbeck KH, Bloem LM, Africander D, Schloms L, Swart P, Swart AC: $11 \beta$-Hydroxydihydrotestosterone and 11-ketodihydrotestosterone, novel C19 steroids with androgenic activity: a putative role in castration resistant prostate cancer? Mol Cell Endocrinol 2013, 377:135-146

47. Moore NL, Hickey TE, Butler LM, Tilley WD: Multiple nuclear receptor signaling pathways mediate the actions of synthetic progestins in target cells. Mol Cell Endocrinol 2012, 357:60-70

48. Wu L, Runkle C, Jin H-J, Yu J, Li J, Yang X, Kuzel T, Lee C: $\mathrm{CCN} 3 / \mathrm{NOV}$ gene expression in human prostate cancer is directly suppressed by the androgen receptor. Oncogene 2014, 33:504-513

49. Munkley J, Oltean S, Vodák D, Wilson BT, Livermore KE, Zhou Y, Star E, Floros VI, Johannessen B, Knight B, McCullagh P, McGrath J, Crundwell M, Skotheim RI, Robson CN, Leung HY, Harries LW, Rajan P, Mills IG, Elliott DJ: The androgen receptor controls expression of the cancer-associated sTn antigen and cell adhesion through induction of ST6GalNAc1 in prostate cancer. Oncotarget 2015, 6 : $34358-34374$ 